\title{
Biogas: olive mill wastewater as complementary substrate of pig- gery effluent
}

\author{
A. Neves, L. Ramalho, L.B. Roseiro, A. Eusébio \& I.P. Marques \\ LNEG-Unit of Bioenergy, Lisboa, Portugal
}

\begin{abstract}
The anaerobic digestion of a peculiar piggery effluent (PE), with a high organic content $(93 \mathrm{~g} / \mathrm{L})$, was carry out using olive mill wastewater (OMW) as complementary substrate. From the different tested conditions - [100\% PE], [70\% PE+30\%OMW], $[50 \% \mathrm{PE}+50 \% \mathrm{OMW}],[20 \% \mathrm{PE}+80 \% \mathrm{OMW}]-$ units containing only PE and the lowest proportion of OMW in the mixture (30\% OMW), provided the highest biogas volume of about $780 \mathrm{~mL}$ (70\% $\left.\mathrm{CH}_{4}\right)$. Comparatively, identical quantities of each substrate ([50\% $\left.\left.\mathrm{PE}+50 \% \mathrm{OMW}\right]\right)$ generates some gas $\left(320 \mathrm{~mL}, 60 \% \mathrm{CH}_{4}\right)$, understood as the result of an adaptation process by the microbial consortium, while the $[20 \% \mathrm{PE}+80 \% \mathrm{OMW}$ condition provided even less gas volume $\left(120 \mathrm{~mL}, 6 \% \mathrm{CH}_{4}\right)$, probably due to the antimicrobial capacity of the phenolic compounds in OMW, confirming the negative influence of using so high OMW proportion.
\end{abstract}

\section{INTRODUCTION}

Portugal owns large breeders (at least 400 pigs and 100 sows) which manage more than two thirds of the pigs fattened before slaughtering, being in a similar situation to countries such as the Czech Republic, Estonia, Ireland, Greece and Cyprus (EUROSTAT 2014). The production of pigs in Portugal was about 2,165,000 heads in 2017, counting for $1.2 \%$ of the Europe production (FAOSTAT 2019). This activity produces high volumes of piggery effluent, which is an unbalanced and, consequently, a potential inhibiting substrate to the anaerobic digestion process, mainly due to high ammonia concentrations. A huge research was done in the scope of inhibiting recalcitrant effluents, involving several arrangements of various pre-treatments processes, which result in very expensive procedures not always achieving good results. The concept of "effluents complementarity" was study and successfully applied to organic effluents by anaerobic digestion, as the case of the OMW treatment. The OMW was digested without chemical correction or pre-treatment by means of a feeding strategy involving an OMW fraction of $83 \%$ (v/v) in admixture with complementary substrate (Marques 2001; Gonçalves et al. 2012). Sampaio et al. (2012) confirmed that the drawbacks of the raw OMW characteristics could be easily overcome by applying the same feeding approach through heterotrophic microalgae (Chlorella protothecoides) as OMW complementary effluent. Later on, Assemany et al. (2018) reported the beneficial effect of substrates complementarity on anaerobic processes since the replacement of algal biomass by OMW $(10 \%, \mathrm{v} / \mathrm{v})$ provided a threefold increase in methane production compared to algal digestion alone. According to Sampaio et al. (2011), the use of complementarity concept allows to obtain a stable anaerobic digestion able to degrade OMW in its original composition $(100 \%, \mathrm{v} / \mathrm{v})$, making the process simpler, more flexible and cheaper. The objective of this work was to optimize operational conditions of the anaerobic digestion of a peculiar high organic content piggery effluent by means of the effluent complementarity concept, using OMW as complementary substrate. 


\section{MATERIALS AND METHODS}

\subsection{Substrates}

The substrates assayed were: piggery effluent (PE) collected in Valorgado Company (Salvaterra de Magos, Portugal), using the liquid fraction after main solids removal by a solid-liquid separator, and olive mill wastewater (OMW) collected from an olive mill (Rio Maior, Portugal) using three-phase continuous extraction process.

\subsection{Anaerobic digestion experimental set-up}

Anaerobic digestion assays were carried out in batch mode, under $37 \pm 1^{\circ} \mathrm{C}$, by using glass reactors with $165 \mathrm{~mL}$ total volume. Tested conditions were run in triplicate as designated in Table 1.

Table 1. Scope of the anaerobic digestion experiment.

\begin{tabular}{|c|c|c|}
\hline \multicolumn{3}{|c|}{ Substrates composition $(\%, \mathrm{v} / \mathrm{v})$} \\
\hline PE & OMW & Designation \\
\hline 100 & 0 & {$[100 \% \mathrm{PE}]$} \\
\hline 70 & 30 & {$[70 \% \mathrm{PE}+30 \% \mathrm{OMW}]$} \\
\hline 50 & 50 & {$[50 \% \mathrm{PE}+50 \% \mathrm{OMW}]$} \\
\hline 20 & 80 & {$[20 \% \mathrm{PE}+80 \% \mathrm{OMW}]$} \\
\hline
\end{tabular}

\subsection{Analytical and chromatograph methods}

Performance of the process was monitored by analytical characterizations of all samples and by the volume and quality of the obtained biogas. Total and volatile solids (TS, VS), chemical oxygen demand (COD), total nitrogen (Kjeldahl, TN), ammonium $\left(\mathrm{NH}_{4}{ }^{+}-\mathrm{N}\right)$, and $\mathrm{pH}$, were assayed according to Standard Methods (APHA 2012). Biogas production was monitored by means of a pressure transducer, while the gas composition and volatile fatty acids (VFA) were analysed by chromatographic techniques (Varian 430-GC, TDC; HP-5890, FID, ASTM Standard Method 2000). The characterization of substrates is shown in Tables 2-4.

Table 2. Effluents characteristics: COD and solids

\begin{tabular}{lccccc} 
& $\begin{array}{c}\text { COD } \\
(\mathrm{g} / \mathrm{L})\end{array}$ & $\begin{array}{c}\text { Total solids } \\
(\mathrm{g} / \mathrm{L})\end{array}$ & $\begin{array}{r}\text { Volatile solids } \\
(\mathrm{g} / \mathrm{L})\end{array}$ & $\begin{array}{r}\text { Total nitrogen } \\
(\mathrm{mg} / \mathrm{L})\end{array}$ & $\begin{array}{r}\text { Ammonium nitrogen } \\
(\mathrm{mg} / \mathrm{L})\end{array}$ \\
\hline $\mathrm{PE}$ & $93 \pm 5$ & $47.4 \pm 0.79$ & $31.9 \pm 0.6$ & $4900 \pm 277$ & $3206 \pm 20$ \\
OMW & $106 \pm 1$ & $31.8 \pm 0.04$ & $26.1 \pm 0.2$ & $213 \pm 16$ & $1.4 \pm 1.6$
\end{tabular}

Table 3. Effluents characteristics: $\mathrm{pH}$ values and volatile fatty acids

\begin{tabular}{|c|c|c|c|c|c|c|}
\hline & $\mathrm{pH}$ & $\begin{array}{r}\text { Acetic acid } \\
(\mathrm{mg} / \mathrm{L})\end{array}$ & $\begin{array}{r}\text { Propionic acid } \\
\text { (mg/L acetic) }\end{array}$ & $\begin{array}{c}\text { Isobutyric acid } \\
\text { (mg/L acetic) }\end{array}$ & $\begin{array}{l}\text { Butyric acid } \\
\text { (mg/L acetic) }\end{array}$ & $\begin{array}{l}\text { TOTAL VFA } \\
\text { (mg/L acetic) }\end{array}$ \\
\hline $\mathrm{PE}$ & 7.27 & 1373.0 & 561.8 & 2157.7 & 1545.7 & 5638.2 \\
\hline OMW & 5.09 & 213.0 & 64.0 & 110.4 & 159.5 & 546.9 \\
\hline
\end{tabular}

Table 4. Effluents characteristics: phenols and antioxidant activity

\begin{tabular}{lccc} 
& $\begin{array}{c}\text { Total phenols } \\
\text { (g GAE/L) }\end{array}$ & \multicolumn{2}{c}{ Antioxidant activity } \\
& $(\mathrm{mmol}$ TEAC) & DPPH Inhibition $(\%)$ \\
\hline PE & $0.89 \pm 0.001$ & $1.11 \pm 0.012$ & $80.9 \pm 0.70$ \\
OMW & $3.12 \pm 0.017$ & $0.80 \pm 0.069$ & $60.9 \pm 2.97$
\end{tabular}




\subsection{Quantification of total phenolics content}

Total phenolics content was determined by the Folin-Ciocalteu colorimetric method (Singleton \& Rossi 1965), according to an improved procedure described by Hagerman et al. (2000). Total phenols were expressed as g GAE (gallic acid equivalents)/L by comparison to the gallic acid standard curve. Results were obtained in triplicate.

\subsection{DPPH radical scavenging assay for Antioxidant activity evaluation}

Radical scavenging activity against stable DPPH radical (2,2-diphenyl-2-picrylhydrazyl hydrate) was determined spectrophotometrically. When DPPH reacts with an antioxidant compound, which can donate hydrogen, it is reduced. The changes in color (from deep-violet to light-yellow) were detected at $515 \mathrm{~nm}$ on a UV/visible light spectrophotometer. Radical scavenging activity of samples was measured by a modified method (Brand-Williams et al. 1995). The decreasing of the DPPH solution absorbance indicated an increase of the DPPH radicalscavenging activity. The experiment was carried out in triplicate. Radical scavenging activity (\%) was calculated by the equation 1.

$$
\% \mathrm{DPPH} \text { inhibition }=\left[\left(\mathrm{Abs}_{\mathrm{b}}-\mathrm{Abs}_{\mathrm{f}}\right) / \mathrm{Abs}_{\mathrm{b}}\right] \times 100
$$

where $\mathrm{Abs}_{\mathrm{b}}$ is the absorption of blank ( $\left.\mathrm{t}=0 \mathrm{~min}\right)$ and $\mathrm{Abs}_{\mathrm{f}}$ is the absorption of tested solution ( $\left.\mathrm{t}=30 \mathrm{~min}\right)$.

The antioxidant activity was expressed in mmol TEAC (Trolox Equivalent Antioxidant Capacity), by preparing a standard curve using Trolox as an antioxidant standard.

\section{RESULTS AND DISCUSSION}

\subsection{Effluents}

This particular piggery effluent used is an unusual very concentrated substrate, whose organic matter content resembles OMW concentrations. So, the presence of such high organic concentrations (93-106 g/L COD: Table 2) indicates that there is a great potential for biogas/methane production. On the other hand, this effluent presents complementary characteristics in terms of composition that can be used advantageously to balance the suitable conditions of the anaerobic digestion process. Effectively, the inhibitory capacity of OMW, due to the total phenols concentration $(\approx 3 \mathrm{~g} / \mathrm{L})$, associated with the acid $\mathrm{pH}(5.0)$ (Tables 3 and 4), can be minimized by piggery effluent addition. Furthermore, OMW nitrogen absence (evaluated through total and ammonia nitrogen contents) may also be compensated by the presence of the high nitrogen content of piggery effluent ( $4.9 \mathrm{~g} / \mathrm{L}$ total, $3.2 \mathrm{~g} / \mathrm{L}$ ammonium nitrogen: Table 2$)$.

\subsection{Biogas/methane production}

Biogas production was registered in all tested mixtures without any "lag" phase (Figure 1).

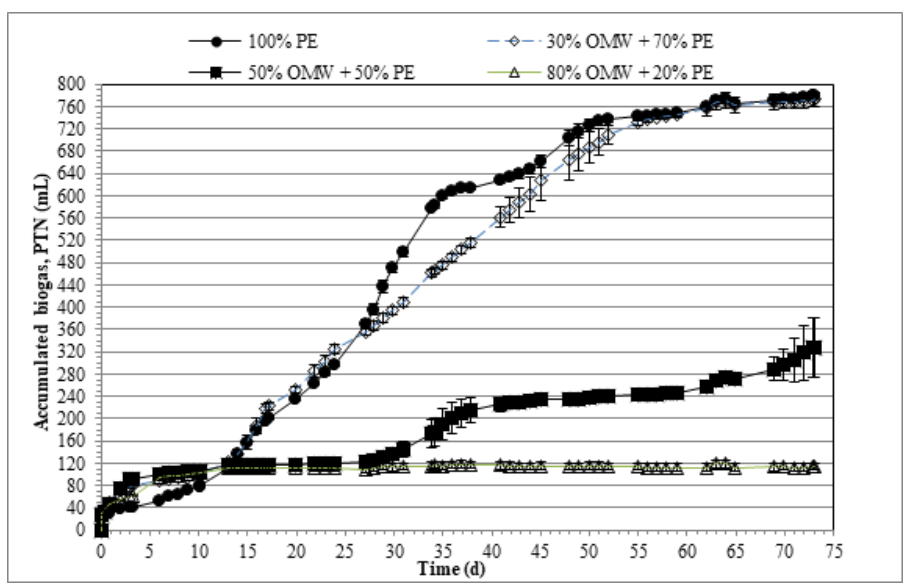

Figure 1. Biogas production 
The biogas production started immediately and a similar accumulated volume $(\approx 120 \mathrm{~mL})$ was observed in all units, elapsed 13 days. From then on, and over the remaining experimental time, units containing $[100 \% \mathrm{PE}]$ and $[70 \% \mathrm{PE}+30 \% \mathrm{OMW}]$ showed a similar behaviour, providing the highest accumulated biogas amount obtained $(\approx 780 \mathrm{~mL})$. For the other two trials, only by the 30 th experimental day, the assay [50\% PE $+50 \% \mathrm{OMW}$ ] was able to generate some gas but it did not exceed the average value of $320 \mathrm{~mL}$. This behaviour can be understood as the result of an earlier process (before the day $30^{\text {th }}$ ) of microorganism adaptation to the effluents mixture, which allowed further increases in gas production. Comparatively, the gas production absence from the assay involving a volume participation of $80 \%$ OMW, suggests that under the tested operating conditions, around $50 \% \mathrm{v} / \mathrm{v}$ is the limiting OMW quantity in the blend. Concerning biogas composition, the units [100\% PE] and [70\% PE+30\%OMW] showed the highest methane concentrations (around 70\% $\mathrm{CH}_{4}$ : Table 5), being in conformity with the previous observations and indicating the presence of a healthy methanogenic archaea population in both assays.

Table 5. Biogas composition

\begin{tabular}{lrr} 
Substrates & $\begin{array}{c}\text { Methane } \\
(\% \mathrm{v} / \mathrm{v})\end{array}$ & $\begin{array}{r}\text { Carbon dioxide } \\
(\% \mathrm{v} / \mathrm{v})\end{array}$ \\
\hline$[100 \% \mathrm{PE}]$ & $71.00 \pm 0.26$ & $29.00 \pm 0.26$ \\
{$[70 \% \mathrm{PE}+30 \% \mathrm{OMW}]$} & $70.27 \pm 0.57$ & $29.73 \pm 0.57$ \\
{$[50 \% \mathrm{PE}+50 \% \mathrm{OMW}]$} & $60.30 \pm 6.68$ & $39.70 \pm 6.68$ \\
{$[20 \% \mathrm{PE}+80 \% \mathrm{OMW}]$} & $5.57 \pm 8.86$ & $94.43 \pm 8.86$
\end{tabular}

The value of $60 \%$ methane in biogas from [50\% PE+50\%OMW] mixture may result from the already referred adaption process of the remaining consortium that had maintained the capacity of converting the substrate and produce biogas/methane. As expected, a very poor biogas was obtained in [20\% PE+80\% OMW], confirming the negative influence on anaerobic consortium if so high OMW proportions are included in the influent.

\subsection{Removal capacity}

The highest amount of organic material removal was observed, as expected, in the units $[100 \% \mathrm{PE}]$ and $[70 \% \mathrm{PE}+30 \% \mathrm{OMW}]$, with $[100 \% \mathrm{PE}]$ being less efficient than [70\%PE+30\%OMW]. Removal values of $63 \%$ against $75 \%$ of initial COD (93 and $81 \mathrm{~g} / \mathrm{L})$ were respectively reached (Table 6). Solids concentrations of 40-47 g/L TS and 28-32 g/L VS ([100\% PE] and [70\%PE+30\%OMW] units (Table 6) were removed in proportion of $17-21 \%$ (TS) and 30-36\% (VS).

Table 6. Chemical oxygen demand and solids

\begin{tabular}{|c|c|c|c|c|c|c|}
\hline \multirow[t]{2}{*}{ Substrates } & \multicolumn{2}{|c|}{ COD } & \multicolumn{2}{|c|}{ Total Solids } & \multicolumn{2}{|c|}{ Volatile Solids } \\
\hline & $\begin{array}{r}\text { initial } \\
(\mathrm{g} / \mathrm{L})\end{array}$ & $\begin{array}{r}\text { removal } \\
(\%)\end{array}$ & $\begin{array}{r}\text { initial } \\
(\mathrm{g} / \mathrm{L})\end{array}$ & $\begin{array}{r}\text { removal } \\
(\%)\end{array}$ & $\begin{array}{r}\text { initial } \\
(\mathrm{g} / \mathrm{L})\end{array}$ & $\begin{array}{r}\text { removal } \\
(\%)\end{array}$ \\
\hline$[100 \% \mathrm{PE}]$ & $93 \pm 5$ & 62.5 & $47.4 \pm 0.79$ & 16.5 & $31.9 \pm 0.56$ & 29.5 \\
\hline$[70 \% \mathrm{PE}+30 \% \mathrm{OMW}]$ & $81 \pm 3$ & 74.6 & $39.6 \pm 0.04$ & 21.0 & $27.8 \pm 0.03$ & 35.6 \\
\hline$[50 \% \mathrm{PE}+50 \% \mathrm{OMW}]$ & $77 \pm 3$ & 47.6 & $38.0 \pm 0.05$ & 16.1 & $27.7 \pm 0.00$ & 22.0 \\
\hline$[20 \% \mathrm{PE}+80 \% \mathrm{OMW}]$ & $73 \pm 1$ & 28.9 & $32.8 \pm 0.60$ & 20.7 & $25.4 \pm 0.61$ & 25.2 \\
\hline
\end{tabular}

VFA contained in digesting substrate of $[100 \% \mathrm{PE}]$ and $[70 \% \mathrm{PE}+30 \% \mathrm{OMW}]$ were more efficiently converted than the other and removal values of 85 and $56 \%$ were registered, respectively (Table 7). As known, most of the methane formed in the anaerobic digestion process results from the acetic acid. In the two present cases, the contribution of acetic acid in total of VFA at baseline was 24 and 58\%, meaning that the remaining VFA correspond to higher-chain acids than acetic and of more difficult degradation, such propionic and butyric (data not shown), justifying the slower initial gas production of these units (Figure 1). This situation presumes the existence of a buffer capacity in the medium capable of maintaining the process balance, for which 
the high amounts of nitrogen in effluents had certainly a positive effect on the digestion process. Initial nitrogen amount (total and ammonia nitrogen; Table 8) decreased with PE decreasing volume, as expected, due to the presence of OMW, characterized by low nitrogen levels.

Table 7. Volatile fatty acids

\begin{tabular}{|c|c|c|c|c|c|}
\hline \multirow{3}{*}{ Substrates } & \multirow{2}{*}{\multicolumn{2}{|c|}{$\begin{array}{c}\text { Acetic acid } \\
(\mathrm{mg} / \mathrm{L})\end{array}$}} & \multicolumn{3}{|c|}{ Total VFA } \\
\hline & & & $(\mathrm{mg} / \mathrm{I}$ & cetic) & $(\%)$ \\
\hline & initial & final & initial & final & removal \\
\hline$[100 \% \mathrm{PE}]$ & 1373 & 688 & 5638.2 & 831.4 & 85.3 \\
\hline$[70 \% \mathrm{PE}+30 \% \mathrm{OMW}]$ & 2314 & 1190 & 3962.0 & 1761.5 & 55.5 \\
\hline$[50 \% \mathrm{PE}+50 \% \mathrm{OMW}]$ & 2175 & 2061 & 3683.9 & 6675.5 & -81.2 \\
\hline [20\%PE+80\%OMW] & 1801 & 757 & 2792.2 & 1328.5 & 52.4 \\
\hline
\end{tabular}

Table 8. Nitrogen

\begin{tabular}{|c|c|c|c|c|c|c|}
\hline \multirow[t]{2}{*}{ Substrates } & \multicolumn{2}{|c|}{$\mathrm{pH}$} & \multicolumn{2}{|c|}{$\begin{array}{l}\text { Total nitrogen } \\
(\mathrm{g} / \mathrm{L})\end{array}$} & \multicolumn{2}{|c|}{$\begin{array}{c}\text { Ammonia nitrogen } \\
(\mathrm{g} / \mathrm{L})\end{array}$} \\
\hline & initial & final & initial & final & initial & final \\
\hline$[100 \% \mathrm{PE}]$ & 7.27 & 8.05 & $4.90 \pm 0.280$ & $\mathrm{n} / \mathrm{d}$ & $3.21 \pm 0.019$ & $3.86 \pm 0.158$ \\
\hline$[70 \% \mathrm{PE}+30 \% \mathrm{OMW}]$ & 6.90 & 7.94 & $1.83 \pm 0.024$ & $1.84 \pm 0.075$ & $1.35 \pm 0.113$ & $2.55 \pm 0.297$ \\
\hline$[50 \% \mathrm{PE}+50 \% \mathrm{OMW}]$ & 6.66 & 7.25 & $1.35 \pm 0.004$ & $1.32 \pm 0.024$ & $0.83 \pm 0.029$ & $0.95 \pm 0.012$ \\
\hline$[20 \% \mathrm{PE}+80 \% \mathrm{OMW}]$ & 6.23 & 5.73 & $0.58 \pm 0.012$ & $0.58 \pm 0.039$ & $0.34 \pm 0.014$ & $0.29 \pm 0.004$ \\
\hline
\end{tabular}

Initial concentrations of total nitrogen were more or less maintained after anaerobic digestion while those relative to ammonia nitrogen were increased due to protein material degradation during the process. The only exception concerns the digestions with the highest proportions of OMW (80\%), which always had the worst results and where the decrease of ammonia nitrogen content confirms the deficient anaerobic digestion functioning, indicating an insufficient activity to perform the degradation/conversion of the organic matter. Accordingly, this mixture emphasized its acidic characteristics during digestion, in which the $\mathrm{pH}$ evolved from 6.2 to 5.7 (Table 8 ), testifying the presence of an imbalanced process in the [20\% PE+80\%OMW] unit, because of the inhibitory conditions establishment. In the other assays, the anaerobic process led to increased $\mathrm{pH}$ values, in a range close to neutrality (6.7-7.3 to 7.3-8.1).

The phenolics content (Total phenols, TP; Table 9) rise as the PE amount decreases in the initial substrates, indicating that OMW is mainly responsible for this increase and, subsequently, the highest TP content was found in admixtures containing OMW. The opposite is observed in relation to the antioxidant activity (Table 9). Doesn't seem to be significant difference for the initial values of the antioxidant activity (ranging 0.9-1.1 mmol TEAC and 68-81\% DPPH radical inhibition). One should bear in mind that different type of phenolics compounds is involved in both PE and OMW, and also, total phenolic content doesn't necessarily correlates with antioxidant activity. Nevertheless, after digestion, it was verified that the lowest antioxidant values were observed in units with highest PE amount ([100\%PE] and [70\% PE+30\%OMW]).

Table 9. Total phenols and antioxidant activity

\begin{tabular}{|c|c|c|c|c|c|c|}
\hline \multirow[t]{3}{*}{ Substrates } & \multirow{2}{*}{\multicolumn{2}{|c|}{$\begin{array}{r}\text { Total phenols } \\
\text { (g GAE/L) }\end{array}$}} & \multicolumn{4}{|c|}{ Antioxidant activity } \\
\hline & & & \multicolumn{2}{|c|}{$(\mathrm{mmol}$ TEAC) } & \multicolumn{2}{|c|}{ DPPH Inhibition (\%) } \\
\hline & initial & final & initial & final & initial & final \\
\hline$[100 \% \mathrm{PE}]$ & $0.89 \pm 0.001$ & $0.86 \pm 0.001$ & $1.11 \pm 0.01$ & $0.64 \pm 0.10$ & $80.9 \pm 0.70$ & $30.3 \pm 8.32$ \\
\hline$[70 \% \mathrm{PE}+30 \% \mathrm{OMW}]$ & $1.69 \pm 0.001$ & $1.10 \pm 0.000$ & $1.07 \pm 0.02$ & $0.39 \pm 0.08$ & $78.6 \pm 0.29$ & $9.7 \pm 6.58$ \\
\hline$[50 \% \mathrm{PE}+50 \% \mathrm{OMW}]$ & $2.18 \pm 0.000$ & $1.52 \pm 0.003$ & $0.99 \pm 0.02$ & $1.34 \pm 0.03$ & $73.7 \pm 1.37$ & $69.1 \pm 1.66$ \\
\hline$[20 \% \mathrm{PE}+80 \% \mathrm{OMW}]$ & $2.69 \pm 0.002$ & $2.50 \pm 0.001$ & $0.91 \pm 0.01$ & $1.35 \pm 0.02$ & $68.1 \pm 0.21$ & $69.5 \pm 1.50$ \\
\hline
\end{tabular}

$\mathrm{TP}$ concentrations of 1.7 and $2.2 \mathrm{~g} / \mathrm{L}$ were removed in proportions of 30 and $35 \%$ for $[70 \% \mathrm{PE}+30 \% \mathrm{OMW}]$ and $[50 \% \mathrm{PE}+50 \% \mathrm{OMW}]$, respectively, while $[20 \% \mathrm{PE}+80 \% \mathrm{OMW}]$ unit presented a poorer removal amount $(7 \%)$ after digestion. No significant change was observed 
for TP concentration in piggery digestion. However, the antioxidant activity decreased to nearly half of the initial value, revealing that most likely, other compounds than phenolics in PE, which are degraded during digestion, may be responsible for this activity. Therefore, these decrease in antioxidant activity for the anaerobic effluent of [100\% PE] and [70\%PE+30\%OMW], indicates the loss of compounds of interest, however, the beneficial characteristics associated with these parameters were still evident in the digested material. In the two other assays $([50 \% \mathrm{PE}+50 \% \mathrm{OMW}]$ and $[20 \% \mathrm{PE}+80 \% \mathrm{OMW}])$, there was a maintenance or even an increase of the initial values for the antioxidant activity, revealing the importance of the OMW composition for this parameter. From the results obtained, one can infer that it is possible to valorise energetically this peculiar PE, alone or in admixture with a small amount of OMW, through the biogas production, and take additional advantage of the remaining compounds of interest present in the digested material.

\section{CONCLUSIONS}

Piggery effluent can be degraded under anaerobic conditions alone or in admixture with $30 \%$ OMW (v/v). The highest gas volumes $\left(\approx 780 \mathrm{~mL}\right.$ biogas, $\left.70 \% \mathrm{CH}_{4}\right)$ were obtained in both experiments. OMW is a substrate with high inhibiting capacity against the anaerobic digestion probably due to the known antimicrobial capacity of phenolic compounds in it, and only a small fraction such as $30 \%(\mathrm{v} / \mathrm{v})$ can be added to PE without damaging the process.

The low biogas production obtained after using a proportion of $50 \%(\mathrm{v} / \mathrm{v})$ OMW in the blend confirms the inhibitory characteristic of this substrate. However, it was observed that microbiota has the capacity to adapt to substrate disadvantageous characteristics. Then under the same operational condition, a possible extension of experimental time could provide better results. From the available data, there is no relevant advantage in associating OMW with this peculiar PE.

\section{ACKNOWLEDGEMENTS}

This work was financed by national funds through the FCT - Fundação para a Ciência e a Tecnologia, I.P. under the project ERANETLAC/0001/2014, GREENBIOREFINERY - Processing of brewery wastes with microalgae for producing valuable compounds. The authors would like to thank Valorgado and olive oil mill company of Rio Maior (Portugal) for effluents, and Natércia Santos for laboratory assistance.

\section{REFERENCES}

Assemany P., Marques I.P., Calijuri M.L., Silva T.L., Reis A. 2018. Energetic Valorization of Algal Biomass in a Hybrid Anaerobic Reactor. J. Environ. Management 209: 308-315.

APHA. 2012. Standard Methods for examination of water and wastewater, Washington DC.

ASTM D1946-90. 2000. Standard Practice for Analysis of Reformed Gas by Gas Chromatography. ASTM International, West Conshohocken, PA.

Brand-Williams W., Cuvelier M.E., Berset C. 1995. Use of a Free Radical Method to Evaluate Antioxidant Activity Lebensm.-Wiss. u.-Technol. 28: 25-30.

Eurostat. 2014. Pig farming sector - statistical portrait 2014. Access in 27 february 2019, available: http://ec.europa.eu/eurostat/statisticsexplained/index.php/Pig_farming_sector -statistical_portrait_2014

FAOSTAT. 2019. Access in 27 february 2019, available: http://www.fao.org/faostat/en/\#data/QA

Gonçalves M.R., Freitas P., Marques I.P. 2012. Bioenergy Recovery from Olive Mill Wastewater in a Hybrid Reactor. Biomass and Bioenergy 39: 253-260.

Hagerman A., Harvey-Muller I., Makkar H.P.S. 2000. Quantification of tannins in tree-foliage - a laboratory manual for the FAO/IAEA co-ordinated research project. In: Joint FAO/IAEA Working Document, 4-6, IAEA, Vienna.

Marques I.P. 2001. Anaerobic digestion treatment of olive mill wastewater for effluent re-use in irrigation. Desalination 137: 233-239.

Sampaio M., Marques I.P. 2012. Direct Anaerobic Digestion of Olive Oil Mills Wastes using Microalgae as a Complementary Substrate. Proc. of Symposium "Olive Oil Mills Wastes and Environmental Protection" 16-18 October 2012, Chania, Crete.

Sampaio M., Gonçalves M.R., Marques I.P. 2011. Anaerobic digestion challenge of raw olive mill wastewater. Bioresour. Technol. 102(23): 10810-10818.

Singleton V.L. and Rossi J.A. 1965. Colorimetry of total phenolics with phosphomolybdicphosphotungstic acid reagents. Am. J. Enol. Vitic. 16: 144-158 